\title{
Soil mapping as a tool for agricultural management
}

\section{Opinion}

The globalization of agriculture has changed the concepts of how to conduct a farm due to the international market pressure. In addition, concern for the environment and climate change has led farmers to adopt more sustainable techniques. Therefore, it is essential using technologies that enable increasing crop yields and rational use of agricultural inputs, which will minimize environmental impact and maximize the profits of farmers. Precision Agriculture (PA) has been shown to great potential for achieving these goals. The principle of PA is that agricultural fields are not homogeneous, thus spatial variability of crop yield and the factors that control this variability should be thoroughly studied. Therefore, tools which allow understanding the spatial variability of crop yield and their relationships in time and space, as well as factors that control it, has been developed and tested. Geostatistics is one of the most important tool for Precision Agriculture. It was developed by George Matheron and described in his paper entitled Principles of Geostatistics. ${ }^{1}$ In the beginning, Geostatistics was developed for mining, but now many other fields have used its concepts, including Agriculture. Contrary to traditional statistics where independence between samples is generally assumed, geostatistics takes advantage of the fact that samples located in proximity to one another are often more similar than those obtained at large separation distances, i.e., it provides a means of quantifying this spatial correlation. ${ }^{2}$ In a practical way, geostatistics is used to create maps of many agricultural variables such as soil, weed, crop yield etc, in order to apply site-specific management through Kriging interpolation method.

In Brazil, the most common Precision Agriculture technique which has been adopted by farmers is georeferenced soil sampling in order to apply fertilizers in variable-rate or in homogenous zones. However, some important questions still have to be answered. Among these it can highlight: Which sampling design should be adopted? How many samples should be taken? Is kriging always the best interpolation method? How to determine the map quality?

The most common sampling design for Precision agriculture is grid sampling, which consist of creating a regular or irregular geo referenced grid in the crop field. Management zone sampling is another way, based on knowledge of historical management or using an auxiliary variable such as topographic variables, electrical conductivity, yield maps etc. Many factors should be taken into account to choose the most appropriate sampling method, including economic factors and characteristics of the area (i.e., soil type, topography, fertility management, cropping history, irrigation etc). The number of samples is another important issue should be analyzed. Evidently, the more samples taken, the more quality of soil maps ${ }^{3}$ demonstrated that when soil properties are sampled at a similar rate to crop yield, it is possible to understand the cause and effect relationships related to the spatial distribution of crop yield and soil properties. High correlations between soil properties and crop yield can be observed when variables are sampled at a similar intensity. However, sampling soil at a similar intensity to crop yield is not economically feasible on a larger scale. Thus, solutions that provide similar sampling intensity are necessary for the evaluation of soil properties and crop yield. One possibility is the development of sensors that evaluate soil properties at a similar
Volume 3 Issue $6-2016$

\author{
Marcos Sales Rodrigues \\ Department of Agronomy Engineering, Universidade Federal do \\ Vale do São Francisco (Univasf), Brazil
}

Correspondence: Marcos Sales Rodrigues, Department of Agronomy Engineering, Universidade Federal do Vale do São Francisco (Univasf), Petrolina, Pernambuco, Brazil, Tel +558-72I014-833,Email marcos.rodrigues@univasf.edu.br

Received: June 24, 2016 | Published: June 27, 2016

intensity to crop yield such as electrical conductivity sensor, ${ }^{4}$ soil $\mathrm{pH},{ }^{5}$ on-the-go near infrared reflectance spectroscopy or real-time NIRS. ${ }^{6}$

Building a soil map is not a hard task, however, the question is: is this map has quality? In other words, are estimate values similar to real values? Therefore, soil map quality indexes should be performed in order to verify its precision and accuracy. Map quality is typically determined by comparing observed mapped values with those obtained by various quantitative and qualitative analytical techniques. Plots of predicted vs. measured values should always be visually examined to assess prediction quality. One of the quantitative measures is map precision, calculated as the standard deviation of the residuals. Map accuracy, another quantitative measure, is the square of bias, and bias is the average of the residuals. The mean square error (MSE) is the sum of precision and accuracy. Frequently, root mean square error (RMSE) is used to compare interpolation methods because it is expressed in the same unit as the study variable. ${ }^{7}$ Therefore, these indexes can be a valuable tool to verified map quality and it will assist decision-making about sample design, number of samples and interpolation methods. Soil mapping can be a useful tool for agricultural management, however it is still necessary more studies in order to improve map quality and reduce soil sampling cost.

\section{Acknowledgements}

None.

\section{Conflict of interest}

The author declares no conflict of interest.

\section{References}

1. Matheron G. Principles of geostatistics. Economic Geology. 1963;58(8):1246-1266.

2. Mata Lima H. Geostatistic in reservoir characterization: from estimation to simulation methods. Estudios Geol. 2005;61:135-145.

3. Rodrigues MS, Corá JE, Fernandes C. Spatial relationships between soil attributes and corn yield in no-tillage system. Revista Brasileira de Ciência do Solo. 2012;36(2):599-609.

4. Serrano J, Shahidian S, Silva JMd. Spatial and temporal patterns of apparent electrical conductivity: DUALEM vs. Veris Sensors for monitoring soil properties. Sensors (Basel). 2014;14(6):10024-10041. 
5. Schirrmann M, Gebbers R, Kramer E, et al. Soil pH mapping with an onthe-go sensor. Sensors (Basel). 2011;11(1): 573-598.

6. Christy CD. Real-time measurement of soil attributes using on-the-go near infrared reflectance spectroscopy. Computers and Electronics in Agriculture. 2008;61(1):10-19.
7. Mueller TG, Pusuluri NB, Mathias KK, et al. Site-specific soil fertility management: A model for map quality. Soil Science Society of America Journal. 2004;68(6):2031-2041. 